\title{
O arquivo e a circulação de sentidos
}

Vanice Maria Oliveira Sargentini ${ }^{1}$

Résumé: Cet article est basé sur l'affirmation que le sens vient de la matérialité du langage et d'archive et tente de répondre aux questions suivantes: Comment travailler avec la dispersion fragmenté de la parole quand il est plongé dans l'excès de mouvement du discours politique? Comment envisager la production du visible et non visible dans la composition d'archive et du corpus de l'analyse? Ces questions nous amènent à considérer la forte présence et l'ingérence des moyens et des processus de circulation des discours dans la production de sens. Quelques réflexions sur cette question nous amène à $\mathrm{M}$. Foucault, en particulier l'article « Répondre à une question » (1968), tandis que dans sa réflexion sur la description d'archive, qui est soumis à la loi de l'existence d'énoncés et leurs conditions d'urgence, l'auteur indique que la production et le traitement d'énoncé est définie par les limites et les formes de ( i ) la disibilité , ( ii ) la conservation, ( iii ) la mémoire , ( iv ) la réactivation et (v ) l' appropriation.

Mots-clé: Archive; média; discours politique; énoncé.

Resumo: Este artigo pauta-se na afirmação de que o sentido procede da materialidade da língua e do arquivo e procura responder as seguintes questões: Como trabalhar com a dispersão fragmentada dos discursos quando se está mergulhado na política do excesso de circulação dos discursos? Como considerar a produção do visível e do não visível na composição do arquivo e, consequentemente, do corpus de análise? Tais questionamentos levam-nos a considerar a forte presença e interferência dos meios e processos de circulação dos discursos na produção dos sentidos. Algumas reflexões sobre essa problemática conduzem-nos a M. Foucault, em especial no artigo 'Resposta a uma questão' (1968), quando em sua reflexão sobre a descrição do arquivo que está submetido à lei da existência dos enunciados e a suas condições de emergência, o autor indica que a produção e a transformação dos enunciados é definida pelos limites e formas (i) da dizibilidade, (ii) da conservação, (iii) da memória, (iv) da reativação e (v) da apropriação.

Palavras-chave: Arquivo; mídia; discurso político; enunciado.

1 Da análise das sequências discursivas à leitura do arquivo.

Ao afirmar que o sentido não é dado a priori, mas sim procede da materialidade da língua e do arquivo, Maldider e Guilhaumou (1994) indicam que a Análise do discurso (AD) funda-se sobre a investigação desses dois suportes materiais. Pautados em uma discussão teórica sobre arquivo, propomo-nos revisar a atribuição que se deu à noção de arquivo na $\mathrm{AD}$ e avaliar como o desenvolvimento desta teoria motivou e justificou as inflexões dessa noção.

1 Professora Doutora da Universidade Federal de São Carlos - UFSCar - SP 


\section{Conexão Letras}

Em artigo publicado por Pêcheux e seu grupo na revista Buscila, em 1984 (Pêcheux, 2011), observa-se como se tornava inevitável a discussão sobre a problemática da tomada do objeto de análise para a AD. J.Guilhaumou e D. Maldidier, ao ponderarem sobre a 'configuração metodológica inicial' da $\mathrm{AD}$, apontam mudanças na constituição da teoria. A AD passa de uma disciplina de programas e métodos para uma disciplina interpretativa, e nisso está envolvida, consequentemente, a mudança no tratamento do objeto de análise - passa-se da análise das sequências discursivas presentes em um corpus para a operação de leitura do arquivo. Guilhaumou e Maldider (1984 [2011, p.98]), ao refletirem sobre a constituição dos corpora em $\mathrm{AD}$, indicam que "uma nova reflexão sobre a noção de corpus se impunha" à AD desenvolvida nos anos de 1980.

Parece atualmente que as constituições dos corpora em $\mathrm{AD}$, tais como elas foram praticadas nos anos de 1970, resultam, na maior parte dos casos de uma "operação de extração" que recorta dos enunciados as suas condições de produção, o tempo da análise linguística. Por um lado, a seleção das palavras-pivô recorre ao já-lá, às formas de saber já constituídas; ela repousa sobre julgamentos de saber de tipo referencial. Por outro lado, os quadros e domínios semânticos constituídos pelas séries de frases transformadas eliminam a linearidade do discurso, nele substituem uma ordem sobre o modelo de constituição do corpus das frases na teoria gramatical. O perigo do artefato estava bastante próximo. Uma nova reflexão sobre a noção de corpus se impunha. (Guilhaumou e Maldider, 1984 [2011, p.98])

Essa preocupação também é expressa por Pêcheux (1984 [2011]) no artigo "Especificidade de uma disciplina de interpretação”, que se segue ao artigo de Guilhaumou e Maldider (1984 [2011]) na Revista Buscila. Ele explicita que a AD especifica-se por sua relação com a língua, mas não se reduz a ela, uma vez que interage com outras tradições e perspectivas.

Ela (a $\mathrm{AD}$ ) partilha com a tradição lexicométrica a prática de construção de corpus e o recurso eventual a algoritmos informatizados, mas ela não se interdita de supor estruturas sintáticas sob a sucessão das unidades lexicais.

Ela partilha, por outro lado, com as tradições semiológicas e semióticas (que, aliás, designam seus trabalhos como análises de discurso) o cuidado de apreender e de descrever as condições estruturais de existência do sentido, mas sem autorizar a supor estruturas lógico-semânticas subjacentes às sequências discursivas.

Ela partilha, enfim, com a perspectiva arqueológica foucaultiana o cuidado de considerar as condições históricas de existência dos discursos na sua heterogeneidade, mas ela visa a re-introduzir explicitamente no campo a problemática da língua. (PÊCHEUX, 1984 [2011, p. 100])

A essa tripla especificidade, a AD fará sempre intervir a especificidade da língua, compreendendo-a, não como puro sistema, mas como "um real específico que forma o espaço contraditório do desdobramento das discursividades" (PÊCHEUX 1984 [2011, p. 101]). Para atender ao desenvolvimento dessa especificidade, já não será suficiente à AD promover metodologicamente o confronto de sequências discursivas, ou o trajeto de palavras-pivô. Será, então, a leitura do arquivo, com o objetivo de analisar a irrupção de um acontecimento em detrimento da localização de uma formação discursiva, a preocupação para a qual as pesquisas da AD se voltam na terceira época.

Maldidier (1993 [2011]), ao traçar um trajeto na história da AD, a partir do trabalho de M. Pêcheux, afirma que uma nova formulação da $\mathrm{AD}$ se faz quando na teoria dispõe-se a 
enfrentar as imprevisibilidades da história, as histórias singulares, o acontecimento. Esse é, portanto, um movimento central que irá desestabilizar o procedimento por etapas antes desenvolvido pela análise do corpus, sua descrição e sua interpretação, por um procedimento em forma espiral e cumulativa que flagrará momentos de corpus, trajetos nas redes que constituem o enunciado.

Segundo Maldidier (1993[2011, p. 61), "por um estranho percurso, M. Pêcheux reencontra finalmente o Foucault que ele não pôde antes encontrar". E os conceitos de arquivo, acontecimento são incorporados na construção de maquinas paradoxais (como aquele sistema de programação DEREC) que observam os objetos discursivos nesta tensão existente entre a sistematicidade da língua, a historicidade e a interdiscursividade.

Firma-se, então, nas reflexões dos anos 80, a AD como uma disciplina de interpretação, voltada para a leitura do arquivo. Com isso novos desafios são impostos e dentre eles a preocupação de "Como ler o arquivo hoje" - exposta no artigo de Pêcheux (1982), que flagra o divórcio cultural existente entre a vertente da leitura do arquivo da perspectiva dos literatos e a vertente dos cientistas que conduzem, assim, a uma perigosa divisão social do trabalho de leitura.

(Aos literatos), o direito de produzir leituras originais, logo 'interpretações', constituindo, ao mesmo tempo, atos políticos (sustentando ou afrontando o poder local); a outros, a tarefa subalterna de preparar e de sustentar, pelos gestos anônimos do tratamento 'literal' dos documentos, as ditas 'interpretações'. (Pêcheux 1982, p.58)

Pêcheux (1982, p. 60), neste momento, ciente dos riscos que esse modo de leitura pode desencadear - dentre eles "o policiamento dos enunciados, uma normalização asséptica da leitura e do pensamento e um apagamento seletivo da memória" - propõe que se volte para a análise da materialidade da língua na discursividade do arquivo. É neste ponto que a noção de arquivo, a meu ver muito se aproxima daquela pensada por Foucault. Um arquivo não é (ou não é somente, se preferirmos) um conjunto de dados guardados, ele é, por sua prática de leitura, revelador de interesses históricos, políticos e culturais.

\section{Limites e formas da produção e transformação de enunciados}

O arquivo compreendido na perspectiva que Foucault (1968) atribuiu ao termo (o arquivo não é nem conjunto de documentos que uma cultura recolhe como memória e testemunho do seu passado, nem a instituição que se ocupa de conservá-los, o arquivo é, antes de tudo, a lei do que pode ser dito, o sistema que rege o surgimento dos enunciados como acontecimentos singulares), exibe um sentido determinado, cada dispositivo de arquivo estabelece sua própria organização, respeitando a especificidade de um tema, de um acontecimento, de um percurso. Tal compreensão da noção de arquivo, se por um lado sustenta a forma de recorte de um corpus discursivo, por outro, apresenta algumas questões aos estudos da Análise do discurso na atualidade: Como trabalhar com a dispersão fragmentada dos discursos no campo de uma visada quando se está mergulhado na política do excesso de circulação dos discursos? Como considerar essa produção do visível e do não visível na composição do arquivo e, consequentemente, do corpus de análise? Essas questões levam-nos a considerar a forte presença e interferência dos meios e processos de circulação dos discursos na produção dos sentidos. Algumas reflexões sobre essa problemática conduzem-nos de retorno a Foucault, em especial no artigo 'Resposta a uma questão' (1968 [2010]), quando em sua reflexão sobre a descrição do arquivo que está submetido à lei da existência dos enunciados e a suas condições de emergência, o 
autor indica que a produção e a transformação dos enunciados é definida pelos limites e formas (i) da dizibilidade ( sobre o que é possível falar? O que se inscreve como domínio discursivo?), (ii) da conservação (quais enunciados são destinados a passar sem deixar vestígios e quais se cristalizam em nossa memória seja pela recitação, pelo ensino ou pela pedagogia?), (iii) da memória (como a inscrição dos discursos nas formações discursivas os tornam válidos, discutíveis ou definidamente invalidados?), (iv) da reativação (quais são os discursos produzidos em outros épocas que tentamos reconstituir e como?) e (v) da apropriação (como se dá a luta pelo domínio dos discursos?). Neste artigo pretendemos, portanto, avaliar como os meios e processos de circulação dos discursos atravessam esse conjunto de regras que definem o arquivo e produzem sentidos.

Partiremos, então, de dois princípios. O primeiro é o de que os arquivos nunca estão dados, portanto é preciso considerar o problema de sua construção. O segundo é o de que, na esteira de Foucault, o arquivo pode ser definido como o sistema geral da formação e transformação dos enunciados. Articulando esses dois princípios, temos que a construção do arquivo não se dá independente desse sistema de produção e transformação dos enunciados que, por sua vez, responde a um conjunto de regras que, em dada época, e por uma determinada sociedade, definem limites e formas de dizibilidade. Para ficar no domínio dos trabalhos aos quais temos nos me dedicado, tomemos como exemplo o discurso politico produzido em campanha eleitoral que compõe o arquivo do Labor ${ }^{2}$. Na contemporaneidade, o limite da dizibilidade esbarra nas questões jurídicas que regram possíveis processos de ofensa moral, de difamação, entre outros. Assim em resposta à questão sobre 'o que é possível falar', pode-se dizer que a forma e o limite da dizibilidade é inerente ao arquivo, uma vez que só se formarão e se transformarão enunciados dizíveis diante das relações de poder que se instalam na sociedade.

Há também o conjunto de regras que, em dada época e sociedade, define limites e formas de conservação dos enunciados. A recitação, o ensino e a pedagogia atuarão como forma de conservação dos enunciados expressos na materialidade linguística em uma perspectiva que não se reduz ao linguístico. Estende-se a outras semiologias - imagens, gestos. Entretanto, a novidade não está na análise da imagem, mas em considerá-la como objeto de análise. Na historiografia, uma imagem só teria lugar como enunciado se ela tivesse se transformado em "arquivo de alguma coisa" (Salomon 2011, p.33). Um enunciado-imagem deve ser alçado de sua simples figuração para se tornar arquivo. Durante o longo período em que a imagem era tomada apenas como ilustração, e somente o texto escrito impunha a materialidade do arquivo, a imagem era negligenciada no arquivo e deixada de lado no momento da análise. Isso nos faz observar que os arquivos não foram (ou ainda não são), portanto, um justo espaço de preservação e conservação, pois ele é suscetível ao que se reconhece em cada tempo como materialidade que deve compor um arquivo. A própria história da $\mathrm{AD}$ quanto ao trato do discurso político é um exemplo de como a transformação do discurso político passa a exigir que o estatuto da imagem (fixa ou em movimento - por exemplo, em tv ou em sites) passe a ocupar lugar central no arquivo.

Há, portanto, uma ordem do discurso (Foucault 1996), regida por procedimentos externos (o tabu, a segregação e a vontade de verdade) e procedimentos internos (comentários, autoria e disciplina), do qual a conservação do arquivo não se separa. O efeito multiplicador e coercitivo inerente ao comentário, a autoria e à disciplina, estará intrinsecamente envolvido neste processo do que será conservado e do que será descartado. A forma da conservação se dará por um processo da pedagogia e do ensino, por um processo de remissões a enunciados anteriores.

2 Laboratório de estudos do discurso - UFSCar 
Os limites e as formas da memória são agenciados também por relações de saber e poder. A memória que se edifica e se organiza diferentemente em distintas formações discursivas definirá o que cada arquivo reconhece como válido ou discutível. As diferentes formas como estão compostos os arquivos sobre a ditadura na América Latina mostra-nos que a memória dos discursos está firmemente atrelada às formações discursivas nas quais os enunciados estão inseridos.

A sociedade, a partir de um conjunto de regras e não alheia às relações de poder, define os limites e as formas de reativação dos enunciados, selecionando, dentre os discursos de épocas anteriores ou das culturas estrangeiras, quais quer reter, valorizar e reconstruir. Restituídos, esses discursos recebem papéis a desempenhar. São organizados em arquivos que passam a ser redistribuídos. A web tornou-se uma ferramenta democrática e eficaz na redistribuição dos arquivos. Tantos institucionais como pessoais, arquivos contento documentos (escritos e imagéticos) de uma dada época, ao serem reativados produzem na sociedade efeitos diversos. No discurso politico a reativação pode produzir efeito paradoxal. São utilizados tanto para qualificar quanto para desqualificar o homem político.

Muitas vezes de uma forma narcisista ou como um instrumento de resistência (quanto ao direito de redistribuir, reproduzir, manifestar-se), a sociedade define os limites e as formas da apropriação dos discursos. Com o objetivo de chegar mais perto de si, os internautas constroem na web homepages produzindo arquivo que permitirá que se promova a apropriação do autor com o domínio dos seus discursos. Os arquivos on-line passaram de uma simples junção de dados de uma família - de uma forma distinta de guardar fotos, dados familiares, ou seja de uma forma de reacondicionamento - para um reagenciamento (Artières 2011, p. 107) dos dados, que passam então a ter grande visibilidade.

Um exemplo indicado por Artières (2011, p.105) oferece-nos uma indicação do extremo de como a internet torna-se uma ferramenta para mostrar os arquivos. Trata-se do site www.desordre.net de Philippe de Jonckheere, que por acumulação e multiplicação de links, organiza uma forma inusitada de escrita e de arquivamento de si. A partir da imagem de sua garagem, que é ocupada por seus arquivos, é possível abrir gavetas e folhear documentos que ali estão guardados, abrir livros, consultar vídeos etc. As imagens a seguir foram extraídas do site. Ao se clicar com o mouse em uma das caixas-gaveta ao fundo encontram-se os papéis e com novo clique pode-se ler o que está no interior do envelope. O mesmo ocorre com alguns vídeos e livros.

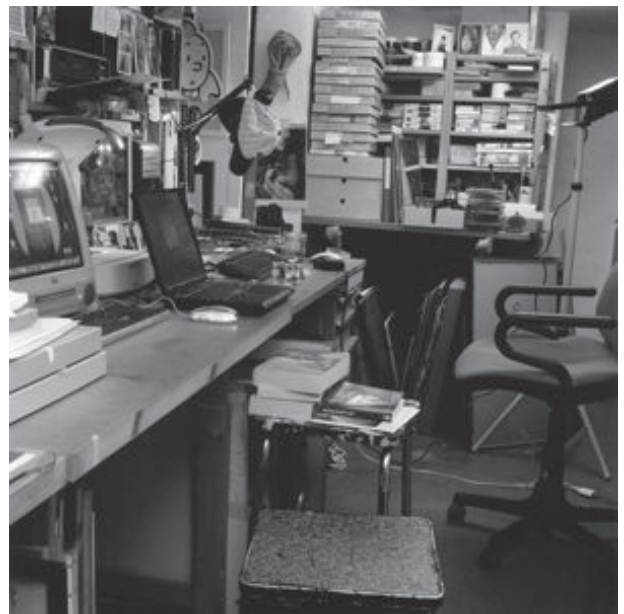

http://www.desordre.net/labyrinthe/garage/photos/017.htm 


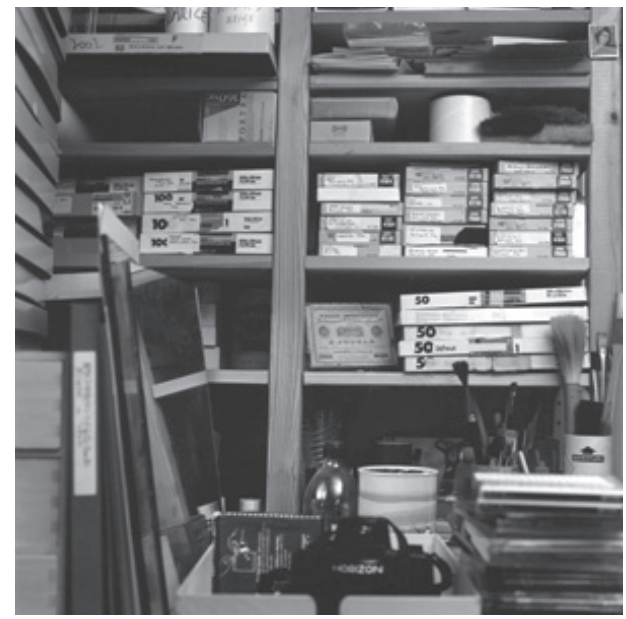

http://www.desordre.net/labyrinthe/garage/photos/020.htm

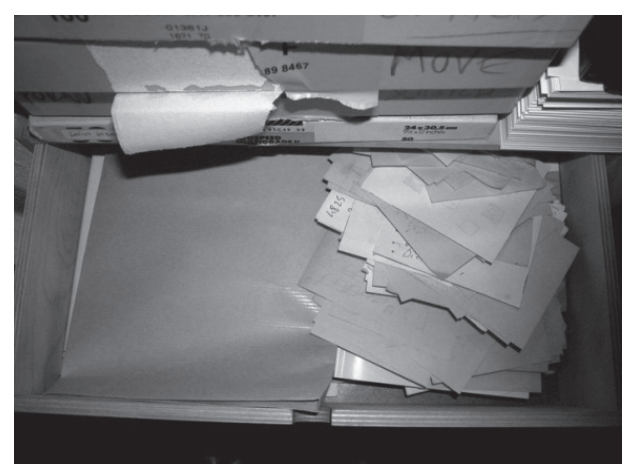

http://www.desordre.net/labyrinthe/garage/photos/tiroirs/035.htm

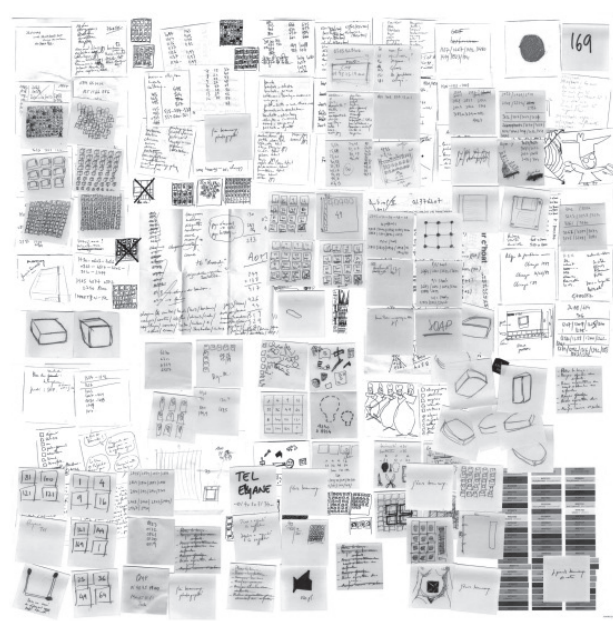

http://www.desordre.net/photographie/numerique/autoportrait_carre/images/grandes/015_notes.htm http://www.desordre.net/labyrinthe/garage/photos/vignettes/index.htm 
A web produz ainda uma economia dos arquivos privados. O acesso a arquivos se era prioritariamente organizado, mantido e cedido por instituições de Estado, hoje, em muitos casos, esse acesso é comercializado. Compra-se o arquivo de programas televisionados, desde palestras a CDs com gravações do Horário Gratuito de Propaganda Eleitoral, por exemplo.

\section{Como trabalhar com a dispersão fragmentada dos discursos no campo de uma visada quando se está mergulhado na política do excesso de circulação dos discursos? Algumas conclusões.}

Em AD, metodologicamente, os trabalhos de pesquisa exigem do pesquisador que ele próprio construa seu arquivo de pesquisa. A noção de arquivo que sustenta nossas reflexões é feita à esteira das proposições de M. Foucault, da Nova História, e das preocupações da $\mathrm{AD}$ da terceira época.

Há, entretanto, na contemporaneidade um excesso do arquivo, mas essa característica, por um lado pode contribuir para a consolidação das sociedades democráticas, já que se torna impossível o controle da circulação dos dados, mas, por outro, o excesso do arquivo induz à repetição e isso pode propiciar o controle da sociedade.

São muitos os arquivos que merecem ser analisados. Em nossas pesquisas temos privilegiado a análise do discurso político considerando suas formas de arquivamento. Como se produz o discurso eleitoral presidencial em campanhas políticas no Brasil? Para responder a essa questão, temos de investigar a organização dos enunciados em diferentes formas de circulação: sites de candidatos ${ }^{3}$, Horário Gratuito de Propaganda Eleitoral ${ }^{4}$ (Garcia e Sargentini, 2010), twitter de eleitoráveis ${ }^{5}$, debates entre candidatos, folhetos de campanha, matérias de jornais e revistas (Carvalho e Sargentini, 2009). Para análise deste arquivo temos que considerar o suporte e as coerções genéricas, por exemplo, o HGPE atribui tempos de apresentação distintos a cada partido, o twitter limita o número de caracteres a serem digitados, os debates têm regras rígidas de participação que envolvem até mesmo a tomada da câmera; a quantidade de informação hoje está marcada mais pela repetição do que pela diversidade, repete-se o dizer, em geral em formas breves, em distintos suportes e em várias materialidades (enunciados escritos, orais, imagéticos); e para a análise é preciso destacar, enfim, a velocidade da informação em relação ao ritmo, que pode ser acelerado, observa-se que há uma sequência muito rápida de imagens (para uma frase curta, apresentam-se 4 ou 5 imagens) que, por vezes, alternam-se com imagens que transcorrem lentamente a fim de marcar traços de docilidade (Sargentini, 2011), paz e harmonia.

Portanto, ler o arquivo hoje significa 'ler a circulação de sentidos', articulando os princípios de dizibilidade, conservação, memória, reativação e apropriação àquele de circulação no qual estão envolvidos o gênero e o tipo de suporte, a quantidade, a intensidade, a velocidade, a materialidade.

3 Geovana Chiari. Propaganda eleitoral na internet: o funcionamento dos sites dos candidatos. 2010. Iniciação científica - Universidade Federal de São Carlos, Apoio CNPq - orientação Vanice M. O. Sargentini.

4 Luciana Carmona Garcia. O discurso político eleitoral contra a corrupção no HGPE/2006: memória e construção de identidade.. 2010. Dissertação de Mestrado em Linguística - Universidade Federal de São Carlos. Apoio Fundação de Amparo à Pesquisa do Estado de São Paulo. Orientador: Vanice Maria Oliveira Sargentini..

5 Lívia Maria Falconi Pires. A política se renova: as novas tecnologias na construção do discurso político.. 2012. Dissertação de Mestrado em Linguística - Universidade Federal de São Carlos. Apoio Coordenação de Aperfeiçoamento de Pessoal de Nível Superior. Orientador: Vanice M.O. Sargentini. 
ARTIÈRES, P. (2011) Monumentos de papel: a propósito de novos usos sociais dos arquivos. in: SALOMON, M (org.) O saber dos arquivos. Goiânia - GO: Edições Ricochete.

CARVALHO, P.H.V. e SARGENTINI, V. (2009) “O papel da imagem em "Uma revista para quem gosta de ler": Piauí." Revista da ANPOLL - multimodalidade e intermidialidade: abordagens linguísticas e literárias. Vol 27. Belo Horizonte - MG, Jan/ Jun.

FOUCAULT, M. (1968) Resposta a uma questão. In: Ditos e escritos VI. Rio de Janeiro: Forense Universitária, 2010. pp.1-24. Original 1968.

FOUCAULT, M. (1996) A ordem do Discurso. Rio de Janeiro: Edições Loyola. GARCIA, L. C ; SARGENTINI, V. M. O. . O discurso político no horário eleitoral gratuito: em direção a uma semiologia da política. In: Gama-Khalil, M; Stafuzza, G.; França, T.M.. (Org.). Análise do Discurso: Sujeito e subjetividade. 1 ed. Uberlândia: Universidade Federal de Uberlândia, 2008, v. 1, p. 493-502.

GUILHAUMOU, J. e MALDIDIER, D. (1984) La configuration méthodologique initial. Buscila (Paris), $\mathrm{n}^{\circ}$ 1. Tradução brasileira de Carlos Piovezani e Vanice Sargentini. A configuração metodológica inicial, pp. 95-98 In: PIOVEZANI, C. e SARGENTINI, V. (orgs.) Legados de Michel Pêcheux.: inéditos em análise do discurso. São Paulo: Contexto, 2011

PÊCHEUX, M. (1984) Spécificité d'une discipline d'interpretation. Buscila (Paris), no 1, pp.56-58. Tradução brasileira de Carlos Piovezani e Vanice Sargentini. Especificidade de uma disciplina de interpretação, pp. 99-103 In: PIOVEZANI, C. e SARGENTINI, V. (orgs.) Legados de Michel Pêcheux.: inéditos em análise do discurso. São Paulo: Contexto, 2011.

PÊCHEUX, M. (1982) Lire l'archive aujourd'hui. in: Archives et Documentos de la Société d'Histoire et épistemologie des sciences du Langage. $\mathrm{n}^{\mathrm{o}} 2$, p. 35-45. Trad. brasileira Ler o arquivo hoje. In: Orlandi, E. (org.) Gestos de Leitura: da História no Discurso. Ed. da Unicamp, 1994, p. 55-64

SALOMON, M. (2011)A danação do arquivo: ensaio sobre a história e a arte das políticas culturais, in: SALOMON, M (org.) O saber dos arquivos. Goiânia - GO: Edições Ricochete.

SARGENTINI, V. (2011) Discurso e História em diferentes materialidades do discurso político. in: INDURSKY, F, MITTMANN, S. e FERREIRA, M.C. L. Memória e História na/ da análise do discurso. Campinas - SP: Mercado de Letras. 